\title{
A Morte em Cena na UTI: A Família Diante da Terminalidade
}

\author{
Mayla Cosmo Monteiro ${ }^{1}$ \\ Andrea Seixas Magalhães \\ Rebeca Nonato Machado \\ Pontifícia Universidade Católica do Rio de Janeiro, Rio de Janeiro, RJ, Brasil
}

\begin{abstract}
Resumo
O presente estudo é parte de investigação mais ampla sobre as repercussões da terminalidade para os familiares de pacientes gravemente enfermos em Unidade de Terapia Intensiva (UTI). Utilizou-se metodologia clínico-qualitativa de pesquisa. Foram entrevistados seis familiares de pacientes em situação de terminalidade em UTI de um hospital privado de médio porte. Da análise do conteúdo das entrevistas, emergiram cinco categorias: percepção sobre a doença e a evolução clínica; impacto da internação em terapia intensiva; percepções sobre a terminalidade; processo de tomada de decisão; e relação com a equipe médica. Neste trabalho, serão apresentadas as três primeiras categorias, com o objetivo específico de discutir percepções e recursos emocionais dos familiares diante da terminalidade. Constatou-se que a morte iminente do paciente promove grande angústia e sofrimento para os familiares, provocando intensas vivências de desamparo. O luto antecipatório foi um recurso adaptativo utilizado pelos membros da família, permitindo assim que reorganizassem seus recursos. Foi evidenciado também um comportamento resiliente entre os familiares, facilitado pelo suporte social e familiar, pela qualidade do vínculo familiar-paciente, pela percepção de que o doente não está sofrendo e pela presença da religião ou da espiritualidade.
\end{abstract}

Palavras-chave: Unidade de terapia intensiva, família, terminalidade.

\section{Death on Stage in the ICU: Family Facing Terminal Condition}

\begin{abstract}
The present study is part of a broader investigation with the purpose of investigating the repercussions of terminal conditions on the families of gravely ill patients hospitalized in Intensive Care Units (ICUs). The study used a qualitative clinical research methodology. Six family members of terminal patients admitted to the ICU of a medium-sized private hospital were interviewed. Five categories emerged from the analysis of the content of the interviews: perception of the illness and clinical progress; impact of admission to intensive care units; perception of the terminal condition; decision-making process; and relationship with the medical staff. This paper will present the first three categories, aiming to discuss the family members' perceptions and their emotional resources in the face of a terminal condition. Evidence shows that the imminent death of the patient generates great distress and suffering for relatives, causing intense experiences of helplessness. Family members used anticipatory mourning as a coping mechanism, allowing them to reassess their resources. Relatives also demonstrated resilient
\end{abstract}

Endereço para correspondência: Pontifícia Universidade Católica do Rio de Janeiro, Departamento de Psicologia, Rua Marques de São Vicente, 225, sala 201L, Gávea, Rio de Janeiro, RJ, Brasil 22451-900. Fone: (21) 3527-1185/3527-1186. E-mail: mayla.cosmo@uol.com.br 
behavior, which was facilitated by social and familial support; the quality of the family-patient bond; the perception that the patient is not suffering; and the presence of religion or spirituality.

Keywords: Intensive Care Unit, family, terminal condition.

\section{La Muerte en Escena: La Familia Ante una Situación Terminal}

\section{Resumen}

Este estudio forma parte de investigación más amplia sobre las repercusiones de una situación terminal para los familiares de pacientes gravemente enfermos en Unidad de Cuidados Intensivos (UCI). Se utilizó metodología clínico-cualitativa de investigación. Fueron entrevistados seis familiares de pacientes en situación terminal en UCI de un hospital privado de porte medio. Del análisis del contenido de las entrevistas emergieron cinco categorías: percepción sobre la enfermedad y la evolución clínica; impacto de la internación en cuidados intensivos; percepción sobre la situación terminal; proceso de toma de decisión; y relación con el equipo médico. En este trabajo serán presentadas las tres primeras categorías, con el propósito de discutir las percepciones y los recursos emocionales de la familia ante la enfermedad terminal. Se constató que la muerte eminente del paciente promueve gran angustia y sufrimiento para los familiares, provocando vivencias intensas de desamparo. El luto anticipatorio fue un recurso adaptativo utilizado por los familiares, permitiendo así que reorganizaran sus recursos. Fue evidenciado un comportamiento infatigable entre los familiares, facilitado por el soporte social y familiar, por la calidad del vínculo familiar-paciente, por la percepción de que el enfermo no está sufriendo y por la presencia de la religión o de la espiritualidad.

Palabras clave: Unidad de cuidados intensivos, familia, situación terminal.

A unidade de terapia intensiva (UTI) destina-se ao atendimento de pacientes graves ou com risco de morte, que requerem assistência médica e de enfermagem permanentes e monitorização contínua (Alcantara, Sant'anna, \& Souza, 2013). A complexidade das ações e dos procedimentos envolvidos nesse ambiente (a gravidade da doença, a necessidade de intubação ou de traqueostomia, de punções, de nutrição enteral e parenteral, etc.) desencadeia situações estressoras e ansiogênicas tanto para o paciente como para sua família, tais como: a impessoalidade do ambiente, a solidão e o isolamento facilitados pela restrição do horário de visitas, o prognóstico incerto ou desfavorável, a falta de informação adequada, o medo da morte, do sofrimento físico e psíquico do paciente e a falta de privacidade e individualidade (Cosmo, Morsch, Goiabeira, Genaro, \& Aragão, 2014).

Nas UTIs, mortes inesperadas como consequências de doenças agudas ou seguidas pelo agravamento de alguma doença de base ocorrem frequentemente, promovendo desequilíbrio no sistema familiar, acompanhado pela percepção de descontinuidade de sua história de vida e por sensações de impotência, de fragilidade e de vulnerabilidade. Ademais, as mortes nessas unidades são sempre processos complexos, com grande risco de promoção da distanásia, caracterizada pela manutenção de tratamentos invasivos em pacientes sem possibilidade de recuperação, submetendo-os a um processo de morte lenta e sofrida (Santana, Rigueira, \& Dutra, 2010).

Face à terminalidade do ente querido, a família se defronta com momentos difíceis de suportar psiquicamente. Walsh e McGoldrick (1998) destacam que atingir o equilíbrio neste processo é a tarefa mais difícil de ser alcançada. A morte ou a ameaça da perda tem um impacto perturbador sobre o equilíbrio funcional; a intensidade da reação emocional está relacionada com o nível de integração emocional da família no momento da perda e com a importância funcional do membro perdido. Uma família mais integrada pode reagir emocionalmente de forma mais direta no momento, mas se adaptar rapida- 
mente; diferentemente, uma família menos integrada, pode demonstrar pouca reação imediata, mas responder posteriormente com problemas físicos ou emocionais (Bowen, 1998; Franco, 2008).

John Rolland (1995), herdeiro da terapia familiar médica (especialidade que tem como objetivo apreender as relações entre as doenças somáticas, os padrões familiares e as dimensões psicossociais), discorre sobre os desdobramentos da doença crônica num contex to desenvolvimental, a partir do cruzamento de três fios evolutivos: os ciclos de vida da doença, do indivíduo e da família. Ele propõe uma Tipologia Psicossocial da doença crônica ou da doença que ameaça a vida, concebida a partir de quatro aspectos: início, curso, consequências e grau de incapacitação da enfermidade. Essa descrição é bastante útil para a equipe de saúde, pois ajuda na compreensão do impacto e das readaptações que a família precisa fazer ao se defrontar com uma doença.

Quanto ao início, as doenças podem ser agudas, como um acidente vascular cerebral (AVC), ou graduais, tal como a doença pulmonar obstrutiva crônica (DPOC). No primeiro caso, há a necessidade de uma mobilização afetiva e instrumental mais rápida para administrar tal adversidade. Nas situações de doenças com início gradual, e que se tornam crônicas, o período de ajustamento é prolongado e a tensão contínua, ocasionando um desgaste emocional e fazendo emergir sentimentos de culpa e de inadequação (Pereira \& Dias, 2007).

Em relação ao curso, as doenças assumem três formas: progressiva, constante e reincidente ou episódica. Nas doenças progressivas, como o câncer, os sintomas são frequentes e progridem em severidade. Nas doenças de curso constante, como o infarto agudo do miocárdio (IAM), existe um momento agudo com a seguida estabilização. O doente se depara com uma mudança semipermanente que é estável e previsível por algum tempo. Quando o curso da doença é reincidente ou episódico, como a asma e a colite ulcerativa, há uma alternância entre períodos de remissão total ou parcial dos sintomas, com períodos de exacerbação destes. É possível manter uma rotina normal, mas há sempre a ameaça da recorrência. Havendo necessidade de internar o membro doente em algumas dessas fases, caberá à família adaptar-se à rotina do hospital, que tem normas e regras bastante peculiares (Santos, 2013).

No que concerne às consequências, as doenças podem ser fatais ou não fatais. Nas doenças não fatais, não há ameaça quanto à duração da vida. Nas doenças fatais, que incluem as enfermidades que encurtam a vida (como a fibrose cística) e aquelas com possibilidade de morte súbita (como a hemofilia ou recorrência de IAM), o doente teme não executar seu plano de vida e a família teme sobreviver sozinha no futuro, havendo em ambos os casos uma tendência à depressão e à separação antecipatória. As famílias, muitas vezes, ficam presas entre um desejo de intimidade e um impulso para afastar-se emocionalmente do doente. A futura expectativa de perda pode dificultar a manutenção da perspectiva de equilíbrio familiar. O clima de constante apreensão e a iminência da morte exacerbam o estado de estresse e tensão (Ferreira \& Mendes, 2013). Persson, Ostlund, Wennman-Larsen, Wengstrom e Gustavsson (2008) realizaram uma pesquisa sobre qualidade de vida em pacientes terminais com câncer de pulmão, e constataram que, logo após o diagnóstico, o funcionamento familiar - coesão, suporte e comunicação entre os membros da família - era compatível com o da população em geral. Porém, com a progressão da doença, tal funcionamento foi se deteriorando, principalmente próximo à morte e até seis meses após sua ocorrência.

Por fim, quanto à incapacitação, esta pode ser cognitiva, sensorial, cinestésica e até social (como no caso de queimaduras severas que são cosmeticamente incapacitantes, levando a uma diminuição na capacidade de interação social). Os diferentes tipos de incapacitação implicam diferenças nos ajustamentos necessários das famílias, como ocorre com a incapacitação cognitiva, que exige mudanças maiores do que quando essa função permanece intacta. A presença ou ausência de qualquer incapacitação significativa é que constitui a principal linha divisória relevante para se construir uma tipologia psicossocial da doença (Rolland, 1995). 
Ademais, quando o início de uma doença coincide com uma transição no ciclo de vida do indivíduo ou da família, as questões relacionadas a perdas anteriores são ampliadas. Do ponto de vista sistêmico, é importante saber a fase do ciclo de vida familiar e o estágio de desenvolvimento individual de todos os membros da família, não apenas do membro doente. A capacidade de cada membro da família de adaptar-se e a rapidez com que o faz estão diretamente relacionadas ao estágio de desenvolvimento de cada indivíduo e ao seu papel na família. Se o membro doente é considerado o protetor e o sustentáculo da família, esta pode se sentir desamparada e apresentar dificuldades na reorganização e na redistribuição de papéis (Rolland, 1995).

Em pesquisa sobre a família diante da iminência da morte em UTI, Ferreira e Mendes (2013) destacam que, quando os familiares recebem a informação sobre a gravidade de seu ente querido, geralmente experienciam um turbilhão de sentimentos, isto é, uma combinação de choque, incerteza, tristeza, confusão, estresse, ansiedade e desconforto. Com frequência, não entendem o que está acontecendo com seu familiar, não sabem para quem perguntar ou como devem se comportar, dando lugar ao medo e ao desamparo. Nesses casos, o enlutamento pode ter início a partir da informação do diagnóstico (Fonseca, 2004).

O luto refere-se ao rompimento de vínculos significativos e tem relação com o grau de investimento afetivo estabelecido pelo enlutado. Quanto maior a vinculação, maior a energia necessária para o desligamento no caso de perda (Parkes, 2009). A experiência de ter um familiar grave internado na UTI pode acionar um mecanismo adaptativo nos membros da família, descrito como luto antecipatório, no qual é possível se preparar cognitiva e emocionalmente para a morte iminente, gerando um intenso sofrimento. $\mathrm{O}$ estudo acerca do luto antecipatório torna-se imprescindível para o trabalho com familiares que passam por períodos longos de internação em hospitais. Entre a descoberta do diagnóstico e a morte propriamente dita do familiar-paciente, as perdas mais comuns são: perda da saúde, afastamento do cotidiano habitual devido à hospitalização e perda do senso de controle e de segurança (Cardoso \& Santos, 2013; Fonseca, 2004; Rando, 2000). Quando a inevitabilidade da morte é deflagrada, esta domina a vida familiar, com predomínio de questões que envolvem separação, tristeza, resolução do luto e vida familiar pós-luto. As famílias têm que gerenciar, portanto, múltiplas demandas no momento terminal de seu ente querido (Gonzaga \& Peres, 2012; Pereira \& Dias, 2007; Schmidt, Gabarra, \& Gonçalves, 2011).

Dessa forma, o cuidado dos familiares é uma das partes mais importantes do cuidado global dos pacientes internados, principalmente por que estes, na maioria das vezes, estão sedados e impossibilitados de tomar decisões (Moritz et al., 2011; Probst, Gustin, Goodman, Lorenz, \& Wells-Di Gregorio, 2016). No âmbito dessas considerações, neste trabalho, buscou-se discutir percepções e recursos emocionais dos familiares diante da terminalidade.

\section{Método}

Realizou-se uma ampla pesquisa ampla com o objetivo de investigar as repercussões da terminalidade para os familiares de pacientes gravemente enfermos em Unidade de Terapia Intensiva (UTI). Foi utilizada uma metodologia clínico-qualitativa, que corresponde a um conjunto de métodos científicos, de técnicas e de procedimentos adequados para descrever e interpretar os sentidos e os significados dados aos múltiplos fenômenos pertinentes ao campo do binômio saúde-doença, relacionados à equipe de profissionais, aos pacientes e familiares (Turato, 2008).

Participaram deste estudo seis familiares de pacientes em situação de terminalidade em UTI de um hospital privado de médio porte. Em relação ao doente, os critérios de inclusão foram: estar internado há mais de 48 horas na UTI e ter como causa da internação doença de base grave e em estado avançado; em relação aos familiares: ser o membro da família responsável pelo paciente e identificado pela equipe multiprofissional como cuidador familiar, e ter sido acolhido pelo serviço de psicologia da unidade. 
Tabela 1

Familiares de Pacientes em Situação de Terminalidade

\begin{tabular}{cccc}
\hline $\begin{array}{c}\text { Identificação } \\
\text { do familiar }\end{array}$ & Parentesco & Dados do paciente & $\begin{array}{c}\text { Tempo de } \\
\text { internação no CTI }\end{array}$ \\
\hline Ana, 70 anos & Filha & Alice, 93 anos, viúva, AVC isquêmico & 45 dias \\
Beatriz, 65 anos & Esposa & Bernardo, 79 anos, câncer com múltiplas metástases & 5 dias \\
Cristina, 78 anos & Mãe & Carlos, 40 anos, câncer de pulmão avançado & 10 dias \\
Denis, 63 anos & Marido & Denise, 63 anos, cirrose hepática avançada & 88 dias \\
Elisa, 79 anos & Esposa & Edson, 84 anos, DPOC avançada e caquexia & 173 dias \\
Francisco, 55 anos & Filho & Filomena, 83 anos, cirrose hepática avançada & 61 dias \\
\hline
\end{tabular}

Foram realizadas entrevistas baseadas em um roteiro semiestruturado, englobando os seguintes tópicos: a percepção sobre a doença e a evolução clínica; relação prévia com paciente e sua representação na família; percepção sobre a comunicação com equipe médica; aspectos valorizados no processo de tomada de decisões e concepções sobre a morte e o morrer.

O contato com os participantes foi facilitado em função da dupla inserção da primeira autora, como psicóloga hospitalar da instituição e como pesquisadora. Todos os familiares entrevistados estavam sendo acompanhados pela psicóloga/ pesquisadora, condição fundamental para a participação na pesquisa, em função da importância do estabelecimento do rapport no contexto estudado, considerando a sensibilidade e a delicadeza que impõe o momento. O convite só era feito após a equipe médica informar à família acerca do agravamento do quadro clínico do paciente e da iminência de morte. As entrevistas aconteceram na sala do Serviço de Psicologia do hospital, e foram agendadas com um dia de antecedência. Fizemos uso também de alguns dados obtidos a partir dos atendimentos psicológicos aos familiares, principalmente os relacionados ao funcionamento familiar. Os cuidados éticos foram observados - assinatura do Termo de Consentimento Livre e Esclarecido e aprovação por Comitê de Ética em Pesquisa. Os nomes utilizados são fictícios.

O método da análise de conteúdo proposto por Bardin (2011) foi utilizado para analisar os dados coletados por meio das entrevistas. A partir do material discursivo, emergiram cinco categorias de análise: percepção sobre a doença e a evolução clínica; impacto da internação em terapia intensiva; percepções sobre a terminalidade; processo de tomada de decisão e relação com a equipe médica. Para atingir o objetivo deste trabalho, serão discutidas as três primeiras categorias. As demais categorias foram discutidas em outros trabalhos divulgados.

\section{Resultados e Discussão}

Em relação aos pacientes, o tempo de internação na UTI foi bastante diversificado, variando entre 5 e 173 dias. Quanto ao tempo vivenciado de terminalidade, temos: morte rápida - entre 5 a 10 dias (Bernardo e Carlos); morte prolongada - por mais de 50 dias (Denise, Edson e Filomena) e morte adiada e incerta, pois paciente apresentou melhora do quadro e teve alta da UTI (Alice).

Corroborando os dados obtidos na literatura (Cosmo et al., 2014; Moritz, Rossini, \& Deicas, 2012), os idosos em situação de terminalidade foram maioria nesta pesquisa. A idade média dos pacientes em UTI vem aumentando nos últimos anos, em função do envelhecimento populacional e do melhor controle das enfermidades crônico-degenerativas. Além disso, os familiares entrevistados são também majoritariamente idosos, ou seja, idosos cuidando de idosos. Uma das características do envelhecimento é a perda 
progressiva da saúde, conjugada com outras perdas - da juventude, da capacidade funcional e laboral, de familiares, de amigos, entre outras. Esse cenário justifica a preocupação com o cuidado dispensado ao idoso, seja ele paciente ou familiar, em especial quando a morte se aproxima (Cosmo et al., 2014). Portanto, no contexto da UTI, a família, além de prestadora de cuidados ao paciente, deve ser também receptora de cuidados da equipe (Kappaun \& Gomez, 2013; Schmidt et al., 2011).

\section{Percepção sobre a Doença e a Evolução Clínica}

A percepção dos familiares sobre a doença relaciona-se com suas dimensões tipológica e psicossocial , conforme descritas por Rolland (1995).-

Mamãe teve um AVC do nada. Ela sempre foi saudável, lógico que ela tem mais de 90 anos e sempre tem uma coisinha aqui e ali, mas nada muito sério. . . E pensar que ela foi ao hortifrutti comprar legumes para fazer um cozido quando aconteceu tudo isso. Ela caiu no chão, ficou desacordada, se urinou toda. . . . Agora ficou do jeito que está, com tubo e sedada. (Ana, filha, 70 anos)

Ontem a médica falou que ele estava muito mal, que ia pro tubo, mas eu não sabia que ele podia morrer, foi um choque. Eu achava que tinha chances dele se recuperar, ele é muito forte e adora a vida. Adora cantar e tocar violão. Nunca pensei que isso podia acontecer logo com ele, que sempre se cuidou. Ele descobriu o câncer há pouco mais de um ano e sempre acreditou que ia ficar curado. No início não queria fazer quimioterapia, acho que porque tinha medo dos efeitos colaterais. Foi um choque para todo mundo, ele não fumava e era muito regrado com sua alimentação. Corria também, participava de várias maratonas [pausa, choro]. (Cristina, mãe, 78 anos)

Doenças agudas surgem no contexto familiar abruptamente e demandam uma rápida adaptação de seus membros (Rolland, 1995). Na fala de Ana, vemos como a doença a surpreendeu, pois não era esperada, apesar da idade avança- da de sua mãe. Essa fase de crise inclui o período inicial de ajustamento e manejo, e envolve questões práticas como aprender a lidar com o ambiente hospitalar, com os procedimentos terapêuticos (sedação e tubo orotraqueal) e com a equipe de saúde (Caiuby \& Andreoli, 2005).

Diferentemente de Ana, Cristina já conhecia o diagnóstico de seu familiar (câncer de pulmão), mas vivenciava uma piora abrupta do quadro clínico deste. Mostrou-se surpresa com a evolução clínica e, por considerar que seu filho era jovem, atleta, regrado com sua saúde e não fumante, acreditava que pudesse livrar-se da morte. Hipotetizamos que ela estivesse na fase da negação, com a presença de choque e descrença, comuns quando o familiar se confronta com uma doença grave que ameaça a vida (Fonseca, 2004).

Ressaltamos a vivência traumática dentro desse contexto de crise, precipitada pelo diagnóstico e pela piora clínica. Segundo Meyer (2007), a noção de crise cobre um terreno abrangente com vários vieses de entrada: agudização de um conflito, ruptura de equilíbrio, intensificação de uma situação de tensão, momento difícil ou perigoso de um processo e desordem acompanhada de busca de solução. Freud (1926/2014) referiu-se ao trauma como um estado de desamparo psíquico, uma situação de impotência realmente experimentada. $O$ trauma é um estímulo precipitante que inicia a cadeia mórbida; o estado traumático é o resultado que se produz ante a ausência de defesas mais ou menos exitosas. A dimensão da surpresa, do susto e do inesperado, presentes no trauma, promove grande angústia e sofrimento, experiência correlata a um sentimento de desamparo subjetivo, vivenciado por alguns dos entrevistados.

Por outro lado, Beatriz narra a progressão da doença de seu marido, que foi avançando de forma insidiosa, sendo revelada por etapas:

Às vezes ele dizia, quando estava na cama, que tinha muitas dores na barriga e que eram gases. Nós íamos pro cinema todo final de semana e ele tinha até deixado de ir porque dizia que se sentia mal de gases. . . 
. Até que ele aceitou ir ao médico e descobrimos que tinha que fazer uma cirurgia oncológica, que ele ia cortar o intestino, mas numa parte em que ele ia ter as funções preservadas. Mas disse que ele tinha também dois pontinhos no figado e que ia ter que fazer uma ablação. Isso foi em junho de 2012. E os médicos disseram que ele teria que fazer acompanhamento com oncologista, que mandou fazer uma tomografia e viu vários pontinhos, e aí começou a quimioterapia. Ele emagreceu muito, chegou a perder 10 quilos. . . . Ele fez uma ressonância magnética, a doutora não falou pra gente, mas a gente lê, e eu vi lá que um termo médico de uma lesão é uma metástase de câncer. Na semana passada nós fomos a consulta e a médica deu um tal de codein [analgésico derivado do ópio, usado para o alívio da dor moderada] para ele e comecei a perceber que ele ficou desorientado e relacionei logo com o remédio. Ele sentava e levantava a noite toda. Aí, logo de manhã, liguei pra médica e ela pediu para reduzir a dose e aumentar o intervalo. Ela disse: "ele tá... com aquela doença... aquilo que a senhora estava sempre tão preocupada aconteceu". (Beatriz, esposa, 65 anos)

A fase crônica da doença de Bernardo foi marcada por limitações físicas, sociais e funcionais, exigindo constante adaptação e ajustamento às novas condições que eram apresentadas gradualmente (cirurgia do intestino, quimioterapia, pontinhos no fígado, suspensão do tratamento). Seja pela dificuldade da médica em explicar a doença e seu prognóstico, seja pela dificuldade de Beatriz em ser mais objetiva e diretiva em suas indagações, e até mesmo em permitir que o paciente participasse mais ativamente de seu tratamento, o fato é que ambos se defrontaram com a gravidade do quadro pouco tempo antes da morte de Bernardo.

Outra familiar também se refere às perdas progressivas e à incapacitação ocasionadas pela doença crônica:

Ele começou a ficar doente há 2 anos, mas nos últimos nove meses ele caiu, até chegar a este ponto. Não queria mais andar, falar, comer era um sacrificio. Tanto que ele chegou aqui desidratado e desnutrido. Foi ficando sem forças e foi se isolando. Muito triste. . . Até que chegou num ponto que tivemos que interná-lo. Esses meses todos temos batalhado ali, junto dele, sempre dando força e carinho. Ele era muito altivo, forte, andava sempre ereto. Vê-lo definhar, andar curvado, cuspindo secreção numa xícara me doía. (Elisa, esposa, 79 anos)

Por algum tempo, o doente (Edson) conseguiu manter-se estável, sendo possível manter a normalidade a despeito da presença "anormal" da doença (DPOC). Mas, seu avanço foi inevitável e comprometeu o doente em todos os níveis de funcionamento, tornando-a irreversível. A fase crônica pode ser longa ou curta, dependendo da evolução da doença e envolve períodos alternados de estabilidade e instabilidade do quadro clínico e incerteza do funcionamento futuro, demandando novas formas de enfrentamento, mudanças nas autodefinições do paciente e da família decorrentes das múltiplas perdas sofridas e períodos extensos de adaptação (Pereira \& Smith, 2005).

$A$ hepatite $C$ começou há 37 anos, quando mamãe foi fazer uma cirurgia, mas, como dizem, ela é silenciosa. Mamãe sempre falava dela, mas a gente achava que ela era mais forte e que a doença nunca ia pegá-la de jeito. Ela adorava viver, viajar, sair com as amigas, estar com a gente e com os netos. Não parecia doente. Dessa vez, ela estava chegando de uma viagem internacional quando começou a se sentir mal. E trouxemos ela pra cá. Os médicos fizeram uma cirurgia, mas não deu certo ... Nos últimos dias, antes de vir para cá, ela estava com sangramento por toda parte. O sangue saía pela boca e pelas fezes. (Francisco, filho, 55 anos)

Como vemos no relato acima, dependendo da personalidade do doente, de sua história de vida e familiar, de suas crenças, a resiliência pode emergir como uma forma de enfrentamento desse período. Tal termo designa a capacidade individual de renascer da adversidade, fortaleci- 
do e com mais recursos, sendo constituído por um ativo processo de resistência, de reestruturação e de crescimento em resposta à crise e ao desafio (Walsh, 2005).

\section{Impacto da Internação em Terapia Intensiva}

Apesar da implantação de programas de humanização nas UTIs, a terapia intensiva ainda remete a sofrimento, morte e falta de humanismo. O desenvolvimento da tecnologia e da farmacologia modernas aplicadas à medicina possibilitou a cura de várias doenças ou sua estabilização, mas, ao mesmo tempo, gerou estruturas mais automatizadas e práticas profissionais tidas como frias e distantes dos pacientes e de suas famílias (Quintana, Kegler, Santos, \& Lima, 2006).

Toca lá o interfone e uma voz diz: "está em procedimento, volta daqui a pouco". O que é isso? Tem que ter alguém de lá de dentro, que abre a porta e olha no meu olho. Nesses meses de idas e vindas no hospital, vi dezenas de pessoas do lado de fora com lágrimas nos olhos, falando com interfone e indo embora. Sabe, abre a porta e explica o que acontece. Isso acalma a gente. (Denis, marido, 63 anos)

Essa expectativa de estar do "lado de dentro do CTI" é bastante presente nos familiares. Estes ficam aguardando, com muita ansiedade, o horário de visita "do lado de fora" (restrito a duas horas por dia no hospital). No caso deste familiar, ele permanecia no hospital das 8 às 22 horas diariamente. Destaca-se também o incômodo gerado pelo interfone, dispositivo tecnológico utilizado para controlar o acesso das pessoas à unidade com o intuito de evitar danos ao paciente. Por outro lado, em outro momento da entrevista, ele se refere à tecnologia da UTI como salvadora da vida de sua esposa:

"A D. chegou aqui muito grave, sangrando muito e se não fosse pela aparelhagem do CTI, ela já teria ido embora, já teria partido" (Denis, marido, 63 anos).

Tal ambivalência relacionada à tecnologia disponível em UTI está presente também em outro relato:
Quando a gente chega aqui e encontra ela sedada, com o tubo, o coração fica apertado, né? Todos aqueles aparelhos ligados nela me apavoram e toda a quantidade de remédios que ela tem que tomar para ficar viva me assustam porque são medicamentos muito fortes. É inacreditável, mas se não fossem esses aparelhos ela não teria chegado até aqui. (Ana, filha, 70 anos)

No contexto da UTI, o cuidado ainda é orientado pelo modelo biomédico, centrado na patologia e nos procedimentos técnicos, em detrimento dos sentimentos, dos receios do sujeito doente e seus familiares e da maneira como vivenciam a situação saúde-doença (Moritz, 2007). Duarte (2003) comenta que as UTIs parecem representar a forma mais aguda da dicotomização doente-doença, ao submeter seus usuários a circunstâncias e condições frequentemente vividas ou representadas como desumanas ou despersonalizantes.

A Associação de Medicina Intensiva Brasileira (AMIB) preconiza que humanizar a UTI significa cuidar do paciente como um todo, considerando o contexto familiar e social, além de englobar medidas para tornar o ambiente físico dessa unidade mais acolhedor e menos impessoal (Souza, 2010). Entretanto, a própria estrutura física da UTI e seu funcionamento contribuem para afastar a família dos cuidados ao paciente, pois além da restrição do horário de visitas, não há cadeiras ou poltronas destinadas a esta. Além disso, há uma rotina própria e específica que, muitas vezes, não considera as necessidades do familiar.

O CTI vive em função de protocolos, mas a vida é maleável, as coisas são maleáveis. Falta sabedoria, jogo de cintura. Falta preparo. Parece que estão fazendo um favor. O CTI se apodera do paciente e o paciente fica sendo propriedade deles, você não pode chegar perto quando quer. Se minha esposa não fosse importante pra mim eu não estaria como estou hoje [choro]. Eu tô muito desgastado porque toda vez que dá 15 ou 20 horas [horários de visita] eu não sei se eu vou ver a minha mulher, porque tem sempre uma coisa. Entendo que tem momentos 
de intercorrência graves e eu espero. Mas dar banho na hora da visita? Então muda o horário de visita ou muda o banho. Isso tudo, ao longo de 4 internações está me desgastando muito. Não existe respeito com o outro lado da porta do CTI. (Denis, marido, 63 anos)

Ao mesmo tempo em que se sentem excluídos do cuidado ao paciente, estranhos, impotentes e angustiados do "lado de fora", sabem que do "lado de dentro" seu ente está recebendo suporte avançado de vida e que, provavelmente, sem isso ele já estaria morto. Importante ressaltar que a relação de Denis com a equipe plantonista transcorreu de forma conflituosa durante a longa internação de sua esposa em UTI (88 dias). O prolongamento da internação, mormente em situações em que o risco de morte é alto e as chances de recuperação são ínfimas, é um fator gerador de estresse tanto para a família como para a equipe de saúde que, também, se sente impotente. Os cuidadores familiares apresentam, com frequência, durante a hospitalização, sintomas como depressão, ansiedade, distúrbios do sono e do apetite, isolamento social e afetivo. Dependendo do tempo de internação, geralmente renunciam a aspectos de sua própria vida para acompanhar o paciente, gerando desde sobrecarga e maior vulnerabilidade até estado de desorganização psicossocial, acompanhado de sentimentos como medo, culpa e raiva (Barros, Andrade, \& Siqueira, 2013; Pereira \& Dias, 2007; Santos, 2013).

Há também a percepção de que a UTI imputa sofrimento ao paciente, ao submetê-lo a procedimentos invasivos e conectá-lo a diversos aparelhos. Em nossa prática, notamos que existe frequentemente uma preocupação por parte do familiar com a dor do paciente.

Ele chegou prostrado. Mexiam nele e ele devia sentir dor, ficava revoltado, desesperado eu acho. E pra poder fazer as coisas tiveram que amarrar ele, ele ficou preso [choro]. É muito ruim a gente ver isso. E ele chamava por mim, me dizia: "me tira daqui, me tira daqui". E eu dizia pra ele ficar quietinho pra poder ser solto, porque eu nem sabia soltar. Um tempo depois os médicos, acho, que deram um tranquilizante, e ele apagou. E é muito ruim ficar sem falar com ele, sem saber como ele está se sentindo. Mas só de vê-lo com a fisionomia que ele não estava na segunda-feira, me tranquiliza, mas não sei até quando terei ele aqui perto. Eu sinto muito mesmo que vou perdê-lo [choro]. (Beatriz, esposa, 65 anos)

Quando o paciente está muito agitado e com o nível de consciência alterado, geralmente este é "contido no leito". Essa cena gera muita angústia na família e é importante que a equipe de saúde reforce que tal procedimento é utilizado para garantir a segurança do paciente, evitando queda do leito, a retirada de acessos e cateteres, etc. Contudo, apesar do sofrimento imposto ao paciente, há um alívio quando este se encontra sedado e com uma "fisionomia tranquila", isto é, quando é silenciado.

Outra peculiaridade presente na UTI é a morte inesperada, que ocorre mesmo após a utilização de toda terapêutica disponível, como, por exemplo, nos casos de trauma ou de choque séptico (Lago, Garros, \& Piva, 2007). Temos, dessa forma, uma situação traumática em que os recursos com os quais o sujeito opera na sua experiência cotidiana foram extrapolados por alguma situação súbita.

Tá muito duro suportar tudo isso, parece que é um pesadelo. Você dorme achando que vai descansar, mas ai vem o pesadelo e te acorda no meio da noite, te deixa assusta$d a$. É assim que me sinto, às vezes acho que não é real, que só preciso de tempo para me recuperar, mas olho para ele com todos esses aparelhos e vejo que é real, muito real. E cada notícia que recebo dos médicos tira mais meu chão [choro]. (Cristina, mãe, 78 anos) A morte ou a ameaça da perda têm um impacto perturbador sobre o equilíbrio funcional de uma família. Familiares que conseguem se comunicar com os ouros membros da família, compartilhar informações e opções, bem como utilizar fontes externas de apoio, parecem enfrentar melhor esse momento (Pereira \& Dias, 2007; Prince-Paul, 2008).

Tenho meus filhos, netos e bisnetos. Mantenho meu pilates, visito os netos para me 
distrair. Sei que eu não posso ir junto, pois sei que sou o esteio para meus filhos. Estamos sempre juntos, nos revezando nas visitas pro Edson nunca ficar sozinho . . . Esse apoio que recebo é que me ajuda a não entregar os pontos. E lá em casa a gente sempre foi de conversar muito e um dá apoio pro outro. Somos muito unidos, todo domingo tem almoço lá em casa e durante a semana os filhos sempre passam pra me ver. Agora, nesses meses de hospital, meu filho tem dormido junto comigo, pois me sinto amparada por ele. (Elisa, esposa, 79 anos) Só que quem sempre acompanhou fui eu. Os filhos só começaram a ficar mais presente no final do ano passado. Sempre sobrou tudo pra mim, eles nunca podiam ficar com o pai, sempre tinham uma desculpa. Quer dizer, apoio, nunca tive. Ontem quando eu falei que queria ficar perto dele no CTI os filhos já foram logo dizendo: "você vai ficar 24 hs? Porque eu não posso, não conte comigo". Se eu pudesse eu levava ele pra casa. Pros filhos ele fica no CTI. (Beatriz, esposa, 65 anos)

Em conformidade com a literatura, o suporte social e familiar é um determinante importante do ajustamento familiar em situações de adoecimento e de perdas (Lima, Amazonas, \& Menezes, 2012; Santos, 2013). O relato de Elisa demonstra como esse suporte é importante para apoio logístico (revezamento dos membros da família durante visita a UTI) e emocional. Por outro lado, a falta de suporte nesses momentos evidencia conflitos prévios, podendo, inclusive, potencializá-los durante a internação, como denota a fala de Beatriz, que nunca pôde contar com a ajuda efetiva dos filhos do primeiro casamento de seu marido.

\section{Percepções sobre a Terminalidade}

O contato brusco e aflitivo com a finitude é, muitas vezes, temido e evitado e requer da família adaptação. $\mathrm{O}$ enlutamento compreende algumas fases, sendo o entorpecimento (presença de choque, incredulidade, descrença e negação) frequente em familiares na UTI (Fonseca, 2004).
Mas será que Deus vai me dar colo se Ele tirar meu filho de mim? Não sei se ainda tenho forças para suportar isso. Converso com ele, digo que ele não pode fazer isso comigo, que ele ainda tem muito para viver, que ainda precisa casar, ter filhos. (Cristina, mãe, 78 anos)

"Imagina se ela morre. Eu invado aquilo lá com tanque de guerra [chora]. Não estou preparado para perdê-la" (Denis, marido, 63 anos).

As falas acima denotam incredulidade, desespero, desamparo e temor de não-sobrevivência psíquica diante da perda iminente de seu familiar querido, pela importância deste na família e pela dependência emocional do familiar em relação ao doente. Vemos, no caso de Denis, que a ameaça de perder sua esposa representa a perda emocional do seu eu, deixando-o mais vulnerável. Já a morte de um filho, como é o caso de Cristina, é considerada pela maioria das pessoas como a maior tragédia da vida, com o agravante de ela ser idosa e já ter perdido outra filha anteriormente (Parkes, 2009; Schmidt et al., 2011).

Além do significado do doente para a família, o momento do ciclo vital familiar também assume importância na compreensão das repercussões emocionais da terminalidade para a família. A morte dos idosos é vista como parte integrante do ciclo de vida familiar, mas não acontece sem estresse.

Minha mãe morrer faz parte da vida, mas é que a gente nunca para pra pensar que isso pode acontecer, mesmo ela tendo 93 anos. Sou muito católica e acho que a vida continua numa outra dimensão. Minha mãe sempre foi muito boa, fez sempre o bem e merece ter um fim sem sofrimento. Não quero que ela morra logo, mas também não quero que ela fique sofrendo. (Ana, filha, 70 anos) Somos católicos, mas minha mãe é espírita. Então a morte é vista de uma outra forma. Ela sempre encarou bem a morte, não tinha medo de perder e nem de morrer. Ela viveu muito bem esses 83 anos de vida . . Ela tinha plena consciência de que ia morrer logo. Ela se despediu de todos. A tecnologia facilitou o contato com os netos que estão 
longe em outras cidades e em outros países. Coloquei eles no Skype e eles se despediram dela [choro]. Inclusive ela fez várias recomendações e pedidos e distribuição formal dos bens dela. Ela também pediu para ser cremada e que levássemos sua urna para o sul, na cidadezinha em que ela nasceu e que tem os pais enterrados e também meu pai. É isso, nossos planos com ela terão que ser interrompidos, pois dessa vez ela não venceu a doença. (Francisco, filho, 55 anos).

No caso dos doentes idosos, apesar da conscientização sobre a proximidade da morte, há sofrimento, principalmente durante a internação na UTI, onde o doente é submetido a vários procedimentos invasivos. Ana mostra-se muito ambivalente, ao mesmo tempo em que não quer que sua mãe morra logo, também não deseja vêla sofrendo. Outro aspecto importante relacionase à qualidade de vida prévia do doente e à qualidade dos vínculos estabelecidos com os familiares. As percepções de que o doente viveu bem sua vida, de que aproveitou os momentos junto aos familiares e de que a relação entre eles era boa, facilitam a aceitação e o enfrentamento. A realização de rituais de despedida (como descrito no relato acima) também beneficia a todos os envolvidos, aproximando a família desse momento final, ao mesmo tempo em que a prepara para a separação, como parte integral do processo de vida (Schmidt et al., 2011).

Perder um filho, como dito, é da ordem do inominável e deixa uma lacuna difícil de preencher. E perder os pais, para muitos, independentemente da idade, é perder a base segura. A morte dos pais faz com que o sujeito se depare com a última etapa de seu próprio ciclo vital, propiciando uma transformação identitária (Walsh \& McGoldrick, 1998).

Além dos fatores supracitados, a religião também contribui como um determinante importante no processo de luto. Corroborando a literatura pesquisada, percebemos em nossa prática, durante o atendimento com as famílias, que a religiosidade ou a espiritualidade ajudam os familiares no enfrentamento da doença grave, promovendo alívio do sofrimento, oferecendo conforto e um significado para tal (Franqueira,
Magalhães, \& Féres-Carneiro, 2015; Pereira \& Dias, 2007; Schmidt et al., 2011).

"Mas entreguei para Deus, seja o que Deus quiser. Você ouviu o médico dizer que o quadro é catastrófico e tenho que começar a me preparar. Mas, sempre existe uma esperança, pra Deus nada é impossivel, né?" (Ana, filha, 70 anos).

"Ele é meu caçula, Deus não pode me tirar ele. Quando ele vai me visitar, chega sempre alegre, cantando, falando 'estou chegando minha velhinha' [choro]. Ele é um filho muito especial. Espero um milagre, tem que acontecer um milagre" (Cristina, mãe, 78 anos).

A expectativa de uma resolução divina, de uma cura milagrosa é reforçada pela fé dos familiares, perpetuando a esperança, entendida como uma forma de sustentação emocional, necessária para que a família consiga acompanhar o doente até os últimos momentos (Ferreira \& Mendes, 2013). Ademais, a morte ou a doença grave em pacientes jovens é considerada como algo que encerra uma vida incompleta, fora do curso normativo, promovendo maior ruptura na família

O luto antecipatório foi um recurso adaptativo utilizado pelos familiares para enfrentar a perda iminente de seu ente querido (Fonseca, 2004; Rando, 2000).

Tá todo mundo chocado, ninguém esperava por isso. Estou muito assustada também. $O$ médico acabou de me dizer assim, nesses termos: "a tomografia está catastrófica, se ela sair da sedação vai ser sem interação" [silêncio]. ... Ninguém tá dormindo direito e os dias ficam muito tristes sem ela. . . A morte da mamãe chegou muito de repente, sem aviso, quer dizer, ela ainda não morreu, mas é como se estivesse praticamente morta, né? (Ana, filha, 70 anos)

Até que acho que deram um sedativo e ele dormiu. A médica pediu para eu esperar do lado de fora e saí com o coração apertado, porque sabia que podia ser a última vez que eu ia estar com ele sem ser nessa situação [silêncio]. Eu preciso muito do meu filho, ele não pode partir [muito choro]. (Cristina, mãe, 78 anos) 
Para esses familiares, a notícia da iminência de morte chegou sem aviso, de forma súbita e repentina. A experiência de antecipação da perda envolve uma gama de respostas emocionais antecipadas como ansiedade de separação, solidão existencial, tristeza, desapontamento, raiva, ressentimento, culpa, exaustão e desespero. Há também algumas fases presentes nesse processo, como o choque, a negação, a ambivalência e a revolta. Como foi discutido, ora o familiar pode desejar estar mais próximo do paciente, ora pode desejar distância e a fuga desta situação insuportável (Fonseca, 2004; Rando, 2000).

$\mathrm{Se}$, por um lado, temos o caráter súbito $\mathrm{e}$ repentino da terminalidade, por outro, temos uma espera longa e uma incerteza quanto ao momento da morte, propiciados pela interferência da tecnologia da UTI no processo do morrer, promovendo certa desestabilização na família, pois ela pode se preparar para a perda iminente e começar a se desligar do doente. $\grave{A}$ medida que a família consegue perceber e assimilar que um de seus membros está em fase terminal, ela pode reorganizar seus recursos para enfrentar a perda iminente de seu ente querido, e assim se preparar para o luto pós-morte. Entretanto, esse processo não elimina o impacto causado pela morte no exato momento em que ela ocorre.

Eu sei que quando a gente tá sem a parte emocional afetada, a morte é uma passagem, que dali pra frente deve ter mais alguma coisa que a gente não sabe por que ninguém voltou para contar. Eu digo isso porque sou católica. Mas quando a gente vê que tá chegando a hora, é diferente. Até hoje eu sinto a morte do meu pai, e agora eu vou perder meu segundo homem. Quando eu chego em casa e vejo tudo dele, no quarto que a gente dormiu essas últimas noites, eu ainda não consegui mexer em nada. Eu só fiz a cama, mas não consigo botar nada pra lavar. Chego em casa e sinto muita falta dele. Sabe, ele era teimoso, mas a gente era cúmplice. (Beatriz, esposa, 65 anos)

Beatriz narra como tem sido difícil viver a vida sem Bernardo, mesmo que por poucos dias. Walsh e McGoldrick (1998) destacam o reconhecimento da realidade da morte como uma dastarefas adaptativas cruciais. No caso de Beatriz, a adaptação torna-se mais penosa, pois as pessoas com quem podia compartilhar essa experiência de perda (os filhos do seu marido) não estão disponíveis emocionalmente para tal. Outro fator dificultador é o histórico de perdas de outras pessoas significativas. Podemos dizer que, nessas situações, o familiar vivencia múltiplos lutos.

Não consigo acreditar que isso está acontecendo de novo. Perdi minha filha do meio há 16 anos e sofri muito. Ela tinha problemas renais desde a adolescência e fez um transplante, que complicou . . . Há 6 meses perdi minha mãe também, perto dela completar 90 anos, e estava triste e ele tentava sempre me animar. Mas não se compara com o que eu estou vivendo agora. Minha mãe já estava bem velhinha, não sofreu e a gente espera, pela ordem natural da vida, que nossos pais vão na nossa frente. Mas perder um filho? Não, não tem palavras. E não é só um, né? São dois que vão deixar um vazio que nada vai preencher [choro] . .. A morte é dor, separação e sofrimento. Não há um único dia que eu não pense na minha filha e acho que vou passar o resto da minha vida pensando agora nos meus dois filhos, morrendo aos poucos [muito choro...]. (Cristina, mãe, 78 anos)

Já perdi muita gente, já sofri demais e ainda sofro, pois sou muito sozinho. Perdi meus pais num acidente em que eu estava, depois o meu tio que foi como um pai para mim, depois perdi uma namorada grávida de um filho meu de 6 meses. Minha vida só recomeçou agora há 2 anos. Então eu acho uma estupidez eu não poder ficar com minha esposa [chora]; ela vai logo embora... [choro] deixa eu ficar com ela, cada hora, minuto, é mais uma hora, um minuto com ela. (Denis, marido, 63 anos)

É fundamental considerar o relacionamento das famílias com as perdas e mortes passadas. Uma sobrecarga de perdas passadas e uma história de dificuldade no manejo dessas perdas parecem prejudicar a capacidade da família de lidar com uma perda atual, deixando seus membros 
mais vulneráveis à depressão, ao luto complicado e ao transtorno do estresse pós-traumático no período pós-morte (Franco, 2008; Wiegand, Grant, Cheon, \& Gergis, 2013).

\section{Considerações Finais}

A morte, apesar de estar inscrita na natureza humana, atinge de maneira muito singular cada ser humano. A reação a este evento depende de inúmeros fatores: características de quem está morrendo (idade, papel na família, o tipo de morte), do enlutado (personalidade, história passada de perdas, religião, suporte social e familiar) e da relação entre eles. No contexto hospitalar, considera-se ainda a complexa teia que se forma entre o médico, o paciente e sua família. Constatamos que a terminalidade do paciente em UTI é atravessada por questões clínicas, familiares, sociais, culturais, religiosas e econômicas, abarcando aspectos multidimensionais.

O prolongamento da internação, como ocorreu com a maior parte dos pacientes, junto com o alto risco de morte, promovem desequilíbrio no sistema familiar, ressaltando a impotência dos seus membros e fazendo emergir sentimentos ambivalentes, pois, ao mesmo tempo em que os familiares não querem que o paciente morra, também não desejam vê-lo sofrendo. Vimos que, como demonstra a literatura, as UTIs promovem a distanásia ao prolongarem o morrer do paciente com doença grave, progressiva e irreversível.

Contudo, encontramos também no grupo dos familiares o comportamento resiliente. Dentre os fatores que facilitaram a aceitação e o enfrentamento desse momento difícil estão o suporte social e familiar, a percepção de que o doente viveu bem a sua vida, a qualidade dos vínculos familiares-paciente, a boa relação com a equipe médica, a percepção de que o doente não está sofrendo, muitas vezes por ter sido silenciado pela sedação, e a presença da religião ou da espiritualidade. Tais fatores são também descritos na literatura como sendo determinantes importantes do ajustamento familiar em situações de adoecimento e de perdas. Com base nesses resultados, ressaltamos a importância da criação de espaços de escuta nos hospitais para os cuidadores familiares, que acolham e propiciem a elaboração dos significados produzidos por eles acerca da doença e da morte de seu ente querido.

\section{Referências}

Alcantara, L., Sant'anna, J. L., \& Souza, M. G. N. (2013). Adoecimento e finitude: Considerações sobre a abordagem interdisciplinar no Centro de Tratamento Intensivo oncológico. Ciência: Saúde Coletiva, 18(9), 2507-2514.

Bardin, L. (2011). Análise de conteúdo. São Paulo, SP: Edições 70.

Barros, S. M. M., Andrade, M. A. C., \& Siqueira, F. A. A. (2013). Cuidar de um familiar com câncer: Contribuições da terapia familiar sistêmica. Pensando Famílias, 17(2), 96-110.

Bowen, M. (1998). A reação da família à morte. In F. Walsh \& M. McGoldrick (Eds.), Morte na familia: Sobrevivendo às perdas (pp. 105-117). Porto Alegre, RS: ArtMed.

Caiuby, A. V. S., \& Andreoli, P. B. A. (2005). Intervenções psicológicas em situações de crise na unidade de terapia intensiva. Relato de casos. Revista Brasileira de Terapia Intensiva, 17(1), 63-67.

Cardoso, E. A. O., \& Santos, M. A. (2013). Luto antecipatório em pacientes com indicação para o transplante de células-tronco hematopoéticas. Ciência: Saúde Coletiva, 18(9), 2567-2575.

Cosmo, M., Morsch, D., Goiabeira, F., Genaro, L., \& Aragão, P. (2014). O paciente em unidade de terapia intensiva - Critérios e rotinas de atendimento psicológico. In K. Kitajima, F. Saboya, J. Marca, \& M. Cosmo (Eds.), Psicologia em unidade de terapia intensiva - Critérios e rotinas de atendimento ( $\mathrm{pp} \mathrm{1-21).} \mathrm{Rio} \mathrm{de} \mathrm{Janeiro,} \mathrm{RJ:}$ Revinter.

Duarte, L. F. D. (2003). Indivíduo e pessoa na experiência da saúde e da doença. Ciência: Saúde Coletiva, 8(1), 173-183.

Ferreira, P. D., \& Mendes, T. N. (2013). Família em UTI: Importância do suporte psicológico diante da iminência de morte. Revista SBPH, 16(1), 88112.

Fonseca, J. P. F. (2004). Luto antecipatório. Campinas, SP: Livro Pleno. 
Franco, M. H. P. (2008). Trabalho com pessoas enlutadas. In V. A. Carvalho, M. H. P. Franco, M. J. Kovàcs, R. P. Liberato, R. C. Macieira, M. T. Veit, ...L. H. C. Barros (Eds.), Temas em psico-oncologia (pp. 398-402). São Paulo, SP: Summus.

Franqueira, A. M. R., Magalhães, A. S., \& Féres-Carneiro, T. (2015). O luto pelo filho adulto sob a ótica das mães. Estudos de Psicologia (Campinas), 32(3), 487-497.

Freud, S. (2014). Inibição, sintoma e angústia. In Obras Completas: Vol. XVII. São Paulo, SP: Companhia das Letras. (Original publicado em 1926)

Gonzaga, L. Z. M., \& Peres, R. S. (2012). Entre o rompimento concreto e a manutenção simbólica do vínculo: Particularidades do luto de cuidadores familiares de portadores de doenças crônico-degenerativas. Vínculo, 9(1), 10-17.

Kappaun, N. R. C., \& Gomez, C. M. (2013). O trabalho de cuidar de pacientes terminais com câncer. Ciência: Saúde Coletiva, 18(9), 2549-2557.

Lago, P. M., Garros, D., \& Piva, J. P. (2007). Terminalidade e condutas de final de vida em Unidades de Terapia Intensiva Pediátrica. Revista Brasileira de Terapia Intensiva, 19(3), 359-363.

Lima, F. A., Amazonas, M. C. L. A., \& Menezes, W. N. (2012). Estratégias de enfrentamiento (coping) de hijos que tienen la madre o el padre internado en una Unidad de Terapia Intensiva (UTI). Diversitas: Perspectivas en Psicología, 8(1), 151-164.

Meyer, L. (2007). Trauma familiar e crise. Jornal de Psicanálise, 40(72), 165-175.

Moritz, R. D. (2007). Como melhorar a comunicação e prevenir conflitos nas situações de terminalidade na Unidade de Terapia Intensiva. Revista Brasileira de Terapia Intensiva, 9(14), 485-489.

Moritz, R. D., Deicas, A., Capalbo, M., Forte, D. N., Kretzer, L. P., Lago, P., ...Ropelato, R. (2011). II Fórum do "Grupo de Estudos do Fim da Vida do Cone Sul": Definições, recomendações e ações integradas para cuidados paliativos na unidade de terapia intensiva de adultos e pediátrica. Revista Brasileira de Terapia Intensiva, 23(1), 24-29.

Moritz, R. D., Rossini, J. P., \& Deicas, A. (2012) Cuidados paliativos na UTI: Definições e aspectos éticos-legais. In R. D. Moritz (Ed.), Cuidados paliativos nas unidades de terapia intensiva (pp. 19-31). São Paulo, SP: Atheneu.
Parkes, C. M. (2009). Amor e perda: As raizes do luto e suas complicações. São Paulo, SP: Summus.

Pereira, L. L., \& Dias, A. C. G. (2007). O familiar cuidador do paciente terminal: $\mathrm{O}$ processo de despedida no contexto hospitalar. Psico, 38(1), 55-65.

Pereira, M. G., \& Smith, T. E. (2005). Biopsychological model in the practice of family therapy. International Journal of Clinical Health Psychology, 6(2), 455-467.

Persson, C., Ostlund, V., Wennman-Larsen, A., Wenagstrom, Y., \& Gustavsson, P. (2008). Health-related quality of life in significant others of patients dying from lung cancer. Palliative $\mathrm{Me}$ dicine, 22, 239-247.

Prince-Paul, M. (2008). Understanding the meaning of social well-being at the end of life. Oncology Nursing Forum, 35, 365-371.

Probst, D. R., Gustin, J. L., Goodman, L. F., Lorenz, A., \& Wells-Di Gregorio, S. M. (2016). ICU versus non-ICU hospital death: Family member complicated grief, Posttraumatic Stress, and Depressive Symptoms. Journal of Palliative Medicine, 19(4), 387-393.

Quintana, A. M., Kegler, P., Santos, M. S., \& Lima, L. D. (2006). Sentimentos e percepções da equipe de saúde frente ao paciente terminal. Paidéia (Ribeirão Preto), 16(35), 415-425. doi:10.1590/ S0103-863X2006000300012

Rando, T. (2000). Clinical dimensions of anticipatory mourning. Chicago, IL: Research Press.

Rolland, J. S. (1995). Doença crônica e o ciclo de vida familiar. In B. Carter \& M. McGoldrick (Eds.), As mudanças no ciclo de vida familiar - Uma estrutura para a terapia familiar (pp. 373-392). Porto Alegre, RS: Artes Médicas.

Santana, J. C. B., Rigueira, A. C. de M., \& Dutra, B. S. (2010). Distanásia: Reflexões sobre até quando prolongar a vida em Unidade de Terapia Intensiva na percepção de enfermeiros. Bioethikos, 4(4), 402-411.

Santos, Q. N. (2013). Estratégia de enfrentamento (coping) da família ante um membro familiar hospitalizado: Uma revisão de literatura brasileira. Mudanças - Psicologia e Saúde, 21(2), 40-47.

Schmidt, B., Gabarra, L. M., \& Gonçalves, J. R. (2011). Intervenção psicológica em terminalidade e morte: Relato de experiência. Paidéia 
(Ribeirão Preto), 21(50), 423-430. doi:10.1590/ S0103-863X2011000300015

Souza, R. P. (2010). Manual de rotinas de humanização em medicina intensiva - AMIB. São Paulo, SP: Atheneu.

Turato, E. R. (2008). Tratado da metodologia da pesquisa clínico-qualitativa: Construção teórico-epistemológica, discussão comparada e aplicação nas áreas da saúde e humanas (3. ed.). Petrópolis, RJ: Vozes.

Walsh, F. (2005). Fortalecendo a resiliência familiar. São Paulo, SP: Roca.

Walsh, F., \& McGoldrick, M. (1998). A perda e a família: Uma perspectiva sistêmica. In F. Walsh \& M. McGoldrick (Eds.), Morte na família: Sobrevivendo às perdas (pp. 27-55). Porto Alegre, RS: ArtMed.
Wiegand, D. L., Grant, M. S., Cheon, J., \& Gergis, M. A. (2013). Family-centered end-of-life care in the ICU. Journal of Gerontological Nursing, 39(8), 60-68. 